\title{
Ambiguitas dalam Humor Parikan/Pantun Kilat Sebagai Pelesetan Makna
}

\author{
M. Hermintoyo \\ Fakultas Ilmu Budaya, Universitas Diponegoro \\ hermintpujangga@gmail.com
}

\begin{abstract}
Language is a communication tool that can be done according to purpose, variety, and media. The goals expected in communicating can be for entertaining, joking and creativity. Creativity can be in the form of works of art, such as rhymes. Pantun in Javanese is called parikan. The constituent elements are bound by the rules of the pantuna form. Ordinary rhyme or four-row rhyme or flash rhyme consisting of two lines. But both must rhyme abab (cross rhyme); each row between four to twelve syllables; the first line is sampiran, the second line is the content (quick rhyme. If the regular rhyme of the first and second rows is sampiran; the fourth row is in the form of contents. The variety used in pantun is a variety of literature. The media can be oral, written, written). can be in print, and in electronic media through the internet. The contents of the pantun can be serious or not, for example the contents are only for humor. Based on the rhyme content data with multiple information / taxa / ambiguity. The tendency of the pantun content ambiguity in the data tends to be interpreted negative / connotative pornography .
\end{abstract}

Keywords: pantun / parikan, sampiran-content, ambiguity, pornography, play / language game.

\section{Intisari}

Bahasa adalah alat komunikasi yang bisa dilakukan sesuai tujuan, ragam, dan medianya. Tujuan yang diharapkan dalam berkomunikasi bisa untuk menghibur, guyon dan berkreativitas. Kreativitas tersebut bisa berupa karya seni, seperti pantun. Pantun dalam bahasa Jawa disebut parikan. Unsur-unsur pembentuknya terikat aturan bentuk pantun. Ada pantun biasa atau pantun empat baris atau pantun kilat yang terdiri dari dua baris. Akan tetapi keduanya harus bersajak abab (rima silang); tiap baris antara empat sampai dua belas suku kata; baris pertama berupa sampiran, baris kedua berupa isi (pantun kilat). Jika pantun biasa baris pertama dan kedua berupa sampiran; baris ketiga keempat berupa isi. Ragam yang digunakan dalam pantun adalah ragam sastra. Media yang digunakan bisa berupa ragam lisan, tulis. Ragam tulis bisa di media cetak, dan di media elektronik melalui internet. Isi pantun bisa serius bisa tidak, misal isinya hanya untuk hiburan berupa humor. Berdasarkan data isi pantun berinformasi ganda/ taksa/ ambiguitas. Kecenderungan keambiguitas isi pantun dalam data cenderung dipelesetkan bermakna konotatif negatif/ pornografi..

Kata Kunci: Pantun/ parikan, sampiran-isi, ambiguitas, pornografi, pelesetan/ permainan bahasa. 


\section{Pendahuluan}

Puisi sebagai ekspresi secara langsung bagi pengarangnya memperrlihatkan kemahiran pengarang dalam berkreativitas, wujudnya bisa berupa pantun/parikan. Parikan termasuk dalam puisi lama yang di dalamnya ada aturan-aturan yang mengikat, seperti adanya jumlah suku kata, rima, dan berapa baris. Jenis pantun ada pantun biasa yang empat baris dengan larik 1 dan 2 sebagai sampiran, 3 dan 4 sesebagai isinya. Ada pula jenis pantun kilat yaitu pantun dua baris; baris pertama sebagai sampiran, baris kedua sebagai isinya. Baik pantun biasa maupun pantun kilat rimanya tetap . Pada pantun kilat rima $a b a b$-nya terletak ditengah dan akhir per larik (Sumarlikah, 2006;19,34; Soetarno,1982:26).

Pantun masih dipergunakan dalam acara adat perkawinan di Betawi, lawakan, dan acara-acara tertentu sebagai pembuka atau penutup. Media pantun tidak hanya dalam lisan, tulis saja, tetapi sudah dalam media sosial di internet. Tujuan berpantun bisa untuk hiburan, misalnya dalam pantun pelesetan. Pemelesetan itu tidak hanya memainkan bunyi, tetapi maknanya juga. Makna tersebut bisa menjadi ambigu. Keambiguan maknanya dipakai sebagai efek lucu. Pelesetan adalah setiap ujaran atau tulisan yang didukung oleh satuan lingual, baik dalam bentuk kata, frasa, klausa, kalimat maupun wacana yang bentuk dan maknanya disimpangkan dari sebenarnya. Misalnya // larang beras dho grundelan/ barange keras nek disogokke dleweran//. Pantun ini pantun kilat dengan larik pertama sebagai sampiran dan larik kedua sebagai isinya. Rimanya abab (sajak silang) terlihat pada kata beras (a) grundhelan (b) di larik pertama, sedangkan pada larik kedua pada keras $(a)$ dan dleweran $(b)$. Isi dari pantun tersebut bermakna ganda atau ambigu bisa berarti konotatif negatif yang porno menggambarkan alat kelamin yang tegang dimasukan ke kelamin wanita mengeluarkan air mani/ air nikmat. Akan tetapi, isi pantun tersebut sebenarnya menggambarkan orang sedang menyikat gigi. Isi pantun ini dipelesetkan sebagai humor/ guyon. Aktivitas seks sebagai pelesetan dari makna sebenarnya. Sudarmo (2004:xiv) mengatakan seks dalam humor adalah kelucuan yang memanfaatkan hal yang porno. Jenis humor porno sangat digemari, sering dalam acara tertentu, nongkrong bersama, jaga malam, lawakan, punya hajat mantenan, acara di radio dst. Seks dalam humor lebih mengena karena seks adalah kebutuhan libido semua manusia normal. Fantasi seks akan memberikan ingatan pengalaman dan keingin- tahuan reaksi jika mendengar aktivitas seks. 
Bahasa pelesetan adalah memelesetkan segala sesuatu yang sudah benar menjadi tidak benar yang secara sengaja agar tercipta kelucuan sebagai sarana kekreatifan seseorang dalam mempermainkan makna. Pelesetan atau imitationand parody, yaitu parodi yang isinya memelesetkan segala sesuatu yang telah mapan atau populer. Sebagai alat eskapisme dari kesumpekan keadaan (Sudarmo, 2004: xii). Pemelesetan ini akan menjadi lucu bagi audiennya atau lawan tuturnya jika antara penutur dan lawan tuturnya mempunyai pengetahuan yang sama tentang kata/ ungkapan serta makna aslinya yang dipelesetan. Penutur dan lawan tutur dalam komunikasi humor sudah paham bahwa dalam pelesetan tersebut ada makna keambiguitasannya, yaitu adanya kemungkinan ada dua pengertian atau lebih (lihat Chaer, 1990:107; Pateda, 1986:91). Karena bersifat ambiguitas ini sehingga kadang-kadang menimbulkan keraguan, kekaburan, ketidakjelasan. Akan tetapi keambiguan itu bisa dilihat dari konteksnya (Hermintoyo, 1998:27).

Kemahiran memelesetkan, secara tidak langsung penutur menguasai linguistik (ilmu bahasa). Hal ini karena kata/ ungkapan yang dipelesetkan menggunakan aturan sistematis dalam teori linguistik, seperti kemampuan memahami kaidah fonologi, morfologi, dan semantik. Selain itu, dalam aspek estetika diperlukan kaidah keindahan dengan menggunakan rima tertentu serta analogi-analogi yang digunakan sebagai gaya bahasa.

Fungsi lain, selain dipergunakan untuk humor yang menghibur dapat dimanfaatkan untuk mengkritik, mengingatkan, menyindir yang dilakukan tanpa beban; bagi pendengarnya bisa memberikan rangsangan rasa gembira dan pengetahuan. Danandjaja (dalam Wijana, 2003:3) menjelaskan humor berfungsi sebagai penglipur lara. Hal ini karena humor dapat menyalurkan ketegangan batin yang yang menyangkut ketimpangan norma masyarakat yang dapat dikendurkan melalui tawa. Humor merupakan suatu genre folklore yang sangat menarik. Walupun terkesan remeh dan bersifat santai, humor dapat dijadikan sebagai alat melihat kecerdasan seseorang atau penuturnya. Humor juga dapat dipergunakan untuk menjadikan pendengar merasa tergelitik perasaannya sehingga terdorong untuk tertawa. Sesuatu yang bersifat menggelitik perasaan itu dapat menimbulkan kejutan, keanehan, ketidakmasukakalan, kebodohannya, sifat pengecohan, kejanggalan, kenakalan, dan keisengan. 
Tertawa yang ditimbulkan oleh humor harus spontan dan bukan terlambat. Tertawa yang spontan sewaktu mendengar humor baru dapat terjadi apabila pendengarnya juga paham dengan konteksnya sehingga tidak perlu dijelaskan terlebih dahulu.

Hermintoyo (2011) menjelaskan dalam proses perubahan kata secara morfologis disebutkan bisa melalui metatesis, substitusi, protesis, epentesis, paragoe, eferesis, sinkop, apakop, pelesapan. Selain itu ditemukan juga humor akibat ambigu/ ketaksaan baik ketaksaan leksikal maupun ketaksaan gramatikal serta gaya bahasanya. Berbicara gaya bahasa tentu berkaitan dengan stilistik yang berkaitan dengan makna. Dalam semantik makna secara umum dibagi denotatif dan konotatif. Makna denotatif adalah makna sebenarnya sedangkan makna konotatif adalah makna yang tidak sebenarnya yang terlihat pada bentuk ungkapan atau peribahasa.

Wijana (2004) menjelaskan bahasa kartun dari kajian pragmatik, yaitu melihat pelanggaran maksim kerja sama. Pelanggaran itu mengakibatkan efek lucu. Selain itu dibicarakan pula aspek kebahasaan ortografis, fonologis, ketaksaan, metonomi, sinonimi, antonimi, eufemisme, nama, deisis, kata ulang, pertalian kata dalam frasa, konstruksi aktifpasif, pertalian antarklausa dan pertalian antarpreposisi.

\section{Metode Penelitian}

Penelitian ini menggunakan metode simak dari teks yang diambil di media WA yang dikirim ke penulis. Data kemudian dibaca berulang-ulang, dipahami apa tujuan dari pantun yang diharapkan dari penulis untuk menunjukkan efek humornya/ kelucuannya, dicatat dan diklasifikasi sesuai dengan tujuan penelitian. Data seluruhnya ada 15 dan diambil semuanya. Data tersebut berupa parikan/ pantun kilat dengan berbahasa Jawa. Pengambilan data parikan dengan alasan parikan/ pantun dikenal dan digemari masyarakat Indonesia. Wujud parikan/ pantun berupa karya berestetika sesuai genre puisi, diperlukan diksi yang tepat, diksi yang berambigu dan konotatif, berima sesuai aturan puisi lama.

Analisis yang digunakan adalah teori konsep humor yang bertumpu pada tiga teori utama, yakni teori ketidaksejajaran, pertentangan, dan teori pembebasan (Wijana, 2003:20-28). Teori ketidaksejajaran mengemukakan bahwa humor secara tidak kongruen menyatukan dua makna atau penafsiran yang berbeda ke dalam suatu objek yang kompleks. Ketidaksejajaran bagian-bagian itu dipresepsikan secara tiba-tiba oleh penikmatnya. Wijana lebih lanjut dengan mengutip pendapat Wilman dikatakan“ ide-ide 
yang tidak konruen itu dapat disatukan dengan bunyi yang sama dan dapat pula salah satu diinferensikan dari yang lain, atau kedua-duanya dibayangkan dapat terjadi dalam kenyataan" Sesuatu yang tidak sejajar menurut paham ketidaksejajaran oleh penganut paham pertentangan dipandang sebagai fenomena pertentangan. Teori pembebasan merupakan penjelasan dari sudut dampak emosional. Humor tidak lain merupakan tipu daya emosional yang seolah mengancam, tetapi akhirnya terbukti tidak ada apa-apanya.

Claire (dalam Astuti, 2009:14) berpendapat humor dapat membuat kelucuan apabila mengandung satu atau lebih dari empat unsur, yaitu: 1) ada kejutan; 2) mengakibatkan rasa malu; 3) ketidakmasukakalan; 4) membesar-besarkan masalah. Keempat unsur itu dapat terlaksana melalui rangsangan verbal berupa kata-kata atau satuan-satuan bahasa yang sengaja dikreasi sedemikian rupa oleh penuturnya. Pengkreasian itu dapat dilakukan dengan permainan bunyi yang berakibat bermakna taksa.; 4) apabila ada resepsi secara psikologis yang kuat dari pihak pendengarnya; 5) pada umumnya harus disajikan dalam keadaan segar, tidak untuk dua kali apalagi untuk ketiga kali bagi pendengar yang sama.

Pendekatan semantik masalah humor berpusat pada ambiguitas yang dilaksanakan dengan mempertentangkan makna (M1) yang memiliki makna berbeda (M2). Ada yang dirasa salah bagi pembaca atau pendengar dari salah satu kata yang dianggap lucu (Astuti, 2009;13; Wijana,2003:23-28).

\section{Hasil dan Pembahasan}

Berikut adalah analisis keambiguan parikan/ pantun kilat:

Data (1) wajik klethik gulane jowo Wulune sithik barange dowo

Data tersebut terjemahannya wajik kletik bergula jawa, bulunya sedikit barangnya panjang. Dalam benak kita pasti membayangkan isi pantun tersebut tentang kelamin lelaki yang panjang bulu kemaluannya sedikit. Akan tetapi isi dari parikan tersebut menjelaskan tentang barang sikat botol. Inilah efek kelucuannya seakan-akan berbicara pornografi sebenarnya tidak. Parikan tersebut bermakna ganda atau ambigu.

\section{Data (2) dientup tawon kemeng rasane}

Dibukak mawon ben kethok apeme

Data (2) isi pantun tersebut berkesan porno karena menjelaskan menyuruh untuk dibuka saja (maksudnya pakaiannya/ celana dalamnya) biar kelihatan vaginanya /dibukak mawon 
ben kethok apeme//. Orang Jawa menyebut alat kelamin wanita adalah apem. Akan tetapi apem yang dimaksud adalah makanan tradisional yang biasanya ada dalam acara bancaan, obo rampenya ada kue apemnya.

\section{Data(3) ono semut neng nduwure uyah}

Lambene ngemut tangane nggrayah

Kepornoan data (3), isi dari pantun tersebut menggambarkan aktivitas seks oral atau mengulum susu dengan tangan gerayangan ke mana-mana. Akan tetapi makna yang tidak negatifnya adalah orang yang sedang bermain seruling. Bermain seruling jenis seruling tarling, cara memainkannya diemut pucuknya, ditiup dengan mulut dan tangannya memainkan lubang serulingnya.

Data (4) weruh wong gemblung marai mules

Ndhuwur diambung kok ngisore teles

Isi data (4) kepornoannya terletak pada larik kedua /dhuwur diambung kok ngisore teles/, artinya di atas dicium tetapi yang bawah basah. Berciuman dan membuat birahi dan kelaminnya jadi basah. Isi dari pantun tersebut sebenarnya menggendong bayi karena gemes diciumi, tetapi bayinya ngompol.

Data (5) Neng sawah nebang tebu

Nek ora mlumah ora iso mlebu

Isi data (5) menggambarkan gaya bersetubuh jika tidak telentang kelamin laki-laki tidak masuk ke kelamin wanitanya /nek ora mlumah ora iso mlebu/. Arti dari isi pantun itu sebenarnya orang memakai sandal. Memakai sandal pasti posisinya telentang kemudian kakinya dimasukkan jika terbalik pasti tidak bisa kaki dimasukkan.

Data (6) trek gandheng amote tebu

Nek ora dijembreng ora mlebu-mlebu

Data (6) isi dari pantun tersebut adalah orang memakai kaos kaki jika tidak dibuka lebar tidak bisa dimasukkan ke kaki. Akan tetapi menjadi bermakna negatif karena bisa diasosiasikan aktivitas seks/nek ora dijembreng ora mlebu-mlebu/ jika tidak dibuka lebarlebar (alat kelaminnya) tidak bisa dimasuki.

Data (7) sego gurih lawuhe sate usus 


\section{Pertamane perih maringono bludas-bludus}

Data (7) isi dari pantun tersebut makna positifnya adalah telinga yang pertama kali dilubangi untuk dipasang tindik/anting-anting pertama kali tersa sakit (perih), tetapi sesudahnya jika sudah sembuh akan mudah dimasuki tindik/ anting-anting tanpa rasa sakit dan tidak ada kesulitan lagi. Makna negatifnya menceritakan malam pertama; bersetubuh pasti ada rasa sakit (perih) karena proses pemerawanan, tetapi sesudahnya tidak ada lagi rasa perih bahkan begitu mudah beraktivitas seksnya /pertamane perih maringono bludas bludus/.

Data (8) pring gading cagak radio

Karo njengking ben tambah jero

Isi negatif dari data (8) menggambarkan gaya bersetubuh dengan posisi cewek sedemikian rupa/nungging agar bisa masuk lebih dalam/karo jengking ben tambah jero/. Akan tetapi isi dari pantun tersebut sebenarnya menjelaskan aktivitas orang sedang mencangkul tanah. Beraktivitas memacul tanah pasti membungkuk atau nungging.

\section{Data (9) Pitik walik nguntal watu}

Wis nggo gaya mulak-malik kok ra metu-metu

Isi data (9) pantun ini sebenarnya menjelaskan seseorang yang sedang mengambil uang di celengan, tetapi kesulitan tidak ke luar uang yang akan diambilnya padahal sudah dilakukan dengan berbagai cara. Akan tetapi menjadi negatif jika berarti aktivitas seks dengan gaya beralih posisi, tetap tidak keluar-keluar air nikmatnya /wis nggo gaya mulak walik kok ra metu-metu/.

\section{Data (10) Becik ketitik olo rupamu \\ Digoyang sitik ben cepet metu}

Informasi data (10) isinya tentang kegiatan arisan, yaitu mengocok siapa nama yang mendapatkan arisan. Akan tetapi informasinya jadi negatif karena dimaknai sebagai aktivitas seks yang tidak hanya diam tetapi perlu bergoyang biar cepat keluar (air nikmatnya)/digoyang sethik biar cepat keluar/.

Data (11) pring gading nggo sunduk tahu 


\section{Posisi njengking ben cepet metu}

Isi data (11) sebenarnya menjelaskan bagaimana cara mengusir tikus di bawah tempat tidur dengan cara menggoyang-goyangkan tempat tidur tersebut supaya tikusnya akan keluar. Akan tetapi menjadi negatif informasinya jika diartikan posisi gaya seks dengan menungging biar cepat keluar air nikmatnya/posisi njengkingben cepet metu/.

\section{Data (12) Kue puthu diwadhahi piring}

Nek ra metu-metu jajal karo miring

Asosiasi yang ditimbulkan dari data (12) isi pantun tersebut menggambarkan adegan yang lama tidak puncak mengeluarkan air nikmatnya sehingga perlu dicoba dengan gaya miring Inek ra metu-metu jajal karo miring/. Akan tetapi, informasi dari isi pantun tersebut sebenarnya menggambarkan orang yang telinganya kemasukan air. Supaya airnya bisa keluar dari telinga bisa dicoba dengan memiringkan kepalanya.

\section{Data (13) awak kurus dikiro mlarat \\ Dikocok terus suwe-suwe muncrat}

Data (13) informasi negatifnya adegan lelaki sedang masturbasi atau aktivitas seks dengan gerakan mengocok lama-lama akan keluar air nikmatnya /dikocok terus suwe-suwe muncrat/. Informasi sebenarnya isi pantun tersebut adalah minum coca cola dengan mengocok isi coca cola di botol, lama-lama jika dibuka akan muncrat air coca colanya.

\section{Data (14) Ono marmut lungguh nang dingklik \\ Rampung dimut kok dadi cilik}

Informasi dari data (14) isi pantun tersebut berasosiasi aktivitas seks oral. Setelah selesai dilakukan seks oral kelamin laki-laki tidak tegang dan besar tetapi menjadi kecil /rampung dimut kok dadi cilik/. Akan tetapi informasi isi pantun tersebut adalah minum permen. Permen jika diminum akan mengecil.

Data (15) tuku watu udane deres

Nek wis bar metu neng awak lemes 
Data (15) informasi isi pantun tersebut menggambarkan setelah beraktivitas seks jika sudah keluar air nikmatnya membuat stamina tubuhnya lemas /nek wis bar metu neng awak lemes/. Informasi yang sebenarnya adalah peristiwa orang melahirkan.

Selain bermakna ganda seperti penjelasan di atas, rima akhir dalam parikan/ pantun kilat menggunakan bunyi vokal, dan konsonan yang memberikan bukti bahwa data di atas adalah parikan. Pun karena jumlah baitnya terdiri dari dua baris maka data di atas adalah data parikan/ pantun kilat. Sampiran di baris pertama dan isi di baris kedua. Sampiran sebagai permainan kata tidak ada artinya, di baris kedua sebagai isi yang menunjukkan tujuan dari makna yang diharapkan.

\section{Simpulan}

Berdasar uraian di atas dapat disimpulkan dari 15 parikan/ pantun kilat terdiri dari dua bait dengan rima silang ( $a b a b)$; terdiri dari 8-12 suku kata. Aspek humornya terletak pada larik kedua yang merupakan isi yang bermakna ambigu. Keambiguan parikan tersebut ada makna (M1) dan makna (M2). (M2) berasosiasi pornografi. Keambiguan isi pantun tersebut karena ada informasi ganda yang masing-masing penutur maupun lawan tutur ada pengetahuan yang sama.

\section{Daftar Pustaka}

Astuti, Wiwik Dwi. 2009. Wacana Hiburan dalam “SMS Seru...!!”. Jakarta: Pusat Bahasa Deparetemen Pendidikan Nasional.

Chaer, Abdul.1990. Pengantar Semantik Bahasa Indonesia. Jakarta: Rineka Cipta.

Hermintoyo, M. 1998. "Ketaksaan dalam Bahasa Indonesia," dalam jurnal Lembaran Sastra. No. 23. hlm. 27-35. Semarang: Fakultas Sastra Universitas Diponegoro.

-2011. “Aspek Bunyi Sebagai Sarana Kreativitas Humor," dalam jurnal bidang kebahasaan dan kesusasteraan , Kajian Sastra. Vol.35. No.1 Januari. hlm.14-27. Semarang: Fakultas Ilmu Budaya Undip.

Pateda, Mansyur. 1986. Semantik Leksikal. Flores: Nusa Indah.

Soetarno, 1982. Peristiwa Sastra Melayu Lama. Syurakarta: Widya Duta.

Sudarmo, Darminto M. 2004. Anatomi Lelucon di Indonesia. Jakarta: Kompas.

Sumarlikah.2006. Belajar Sastra Indonesia. Surabaya:Farhas.

Wijana, I Putu. 2003. Kartun Studi: Tentang Permainan Bahasa. Yogyakarta: Ombak. 